\title{
Sex Differences in Metabolism of Trichloroethylene and Trichloroethanol in Guinea Pigs
}

\author{
Yui Hibino ${ }^{1}$, Hailan $\mathrm{WANG}^{2}$, Hisao NAITO ${ }^{1}, \mathrm{Na} \mathrm{ZHAO}^{2}$, Dong WANG ${ }^{1}$, Xiaofang JiA ${ }^{1}$, \\ Hongling $\mathrm{LI}^{2}$, Xiangrong SonG ${ }^{2}$, Lili LiU ${ }^{2}$, Yongshun $\mathrm{HuANG}^{2}$, Yuki ITO ${ }^{3}$, Hanlin $\mathrm{HuANG}^{2}$, \\ Michihiro KamiJima $^{3}$ and Tamie NaKaJima ${ }^{1,4}$ \\ ${ }^{1}$ Department of Occupational and Environmental Health, Nagoya University Graduate School of Medicine, Japan, \\ ${ }^{2}$ Hospital for Occupational Diseases Control of Guangdong Province, Guangzhou, China, ${ }^{3}$ Department of \\ Occupational and Environmental Health, Nagoya City University Graduate School of Medical Sciences, Japan and \\ ${ }^{4}$ College of Life and Health Sciences, Chubu University, Japan
}

\begin{abstract}
Sex Differences in Metabolism of Trichloroethylene and Trichloroethanol in Guinea Pigs: Yui HIBINo, et al. Department of Occupational and Environmental Health, Nagoya University Graduate School of Medicine-Objectives: Trichloroethylene (TRI) has the potential to cause generalized dermatitis complicated with hepatitis. The guinea pig maximization test (GPMT) also suggests that both TRI and its metabolite trichloroethanol (TCE) exhibit immunogenicity and possible sex differences in guinea pigs. However, TRI and TCE metabolisms in guinea pigs have not been elucidated in detail. The first issue to clarify may be the sex differences in relation to the immunogenicity. Methods: We collected urine from Hartley male and female guinea pigs 24 hours after intracutaneous injection of TRI, TCE or trichloroacetic acid (TCA) during a GPMT and measured the urinary metabolites by gas chromatography-mass spectrometry. Results: After TRI treatment, the amount of TCA was significantly greater in females than males, while there was no sex difference in the total amount (TCA + TCE). TCA was only detected in urine after TCA treatment. Interestingly, not only TCE but also TCA was detected in urine of both sexes after TCE treatment, and the amount of TCA was also greater in females than males. An additional experiment showed that TCE treatment did not result in the detection of urinary TCA in cytochrome P450 (CYP)2E1-null mice
\end{abstract}

Received Apr 23, 2013; Accepted Jul 3, 2013

Published online in J-STAGE Sept 10, 2013

Correspondence to: H. Naito, Department of Occupational and Environmental Health, Nagoya University Graduate School of Medicine, 65 Tsurumai-cho, Showa-ku, Nagoya, Aichi 466-8550, Japan (e-mail:naitoh@med.nagoya-u.ac.jp)

Abbreviations: CYP2E1, cytochrome P450 2E1; GC-MS, gas chromatography-mass spectrometry; GPMT, guinea pig maximization test; TCA, trichloroacetic acid; TCE, trichloroethanol; TRI, trichloroethylene but did in wild-type mice, suggesting the involvement of CYP2E1 in the metabolism from TCE to TCA. The constitutive expression of CYP2E1 in the liver of guinea pigs was greater in females than males. Conclusions: The sex difference in urinary TCA excretion after TRI and TCE treatments may be due to variation of the constitutive expression of CYP2E1.

(J Occup Health 2013; 55: 443-449)

Key words: Cytochrome P450 2E1, Guinea pig, Trichloroacetic acid, Trichloroethanol,

Trichloroethylene

Trichloroethylene (TRI) has been used industrially as a degreasing agent for metal materials and lenses. Its use has been decreasing in the developed countries, however, it is still used in industrializing countries because of its superior degreasing power, noncombustibility and cheaper $\operatorname{cost}^{1)}$.

TRI is carcinogenic to humans ${ }^{2)}$ and poses potential adverse effects on the human central nervous system, liver, kidney, and immune system, and also on animal reproductive organs ${ }^{3,4)}$. Regarding its influence on the immune system, there are at least two kinds of pathological abnormality: one is generalized hypersensitive dermatitis complicated with severe hepatitis ${ }^{5,6)}$, and another is autoimmune hepatitis, which is observed in patients with scleroderma or systemic lupus erythematosus $^{7,8)}$. In the former case, typical pathogenesis is to be lain in the onset time: this disease cannot occur immediately after TRI exposure, but only after repeated exposure to TRI for 3-4 weeks ${ }^{9)}$. Therefore, patients with this disease may have delayed-type hypersensitivity.

In mammals, TRI is metabolized mainly by cytochrome P450 (CYP) 2E1 to chloral hydrate ${ }^{10,11)}$, and 
then converted to trichloroethanol (TCE) and trichloroacetic acid (TCA) by alcohol dehydrogenase and aldehyde dehydrogenase, respectively ${ }^{12)}$. The TCE produced is further metabolized to its conjugated form by uridine 5'-diphospho-glucuronosyltransferase, while it is metabolized to TCA via chloral hydrate ${ }^{12)}$. The latter metabolic pathway, as well as TRI metabolism, has been well investigated in mice and rats but not in guinea pigs. Since guinea pigs were used to investigate the immune response to some chemicals including $\mathrm{TRI}^{13)}$ and its metabolites ${ }^{14)}$ using the so-called guinea pig maximization test (GPMT), the metabolic pathway of TRI and TCE in guinea pigs should be clarified in these animals. Also, TRI-induced acute hepatotoxicity and autoimmune hepatitis are heavily related to metabolism ${ }^{11,15,16)}$, suggesting that metabolism may also be related to TRI-induced generalized hypersensitive dermatitis complicated with hepatitis. In this regard, sensitization to TRI was observed in both male $(70 \%)$ and female $(90 \%)$ guinea pigs, but sensitization to TCE was only observed in females $(50 \%)^{14)}$, suggesting the importance of study on sex differences in their metabolism in guinea pigs. Sensitization to TCA was not observed in this experiment.

In order to address this issue, we measured urinary metabolites of TRI, TCE and, as a reference of their final metabolite, TCA in guinea pigs and also investigated the contribution of CYP2E1 in the metabolic pathway from TCE to TCA using wild-type and CYP2E1-null mice.

\section{Materials and Methods}

\section{Animals}

1) Guinea pigs

This study was conducted according to the animal experimental guidelines of Guangdong Poison Control Center in China. Specific pathogen-free Hartley guinea pigs weighing 300-400 $\mathrm{g}$ were used for the GPMT. They were housed in a suspended stainless steel metabolic cage ( 5 per cage) in a room with a 12 hours light: 12 hours dark cycle, stable relative humidity $(40-70 \%)$ and a constant temperature $\left(20-25^{\circ} \mathrm{C}\right)$. Food and water were provided ad libitum.

In order to detect hepatic CYP2E1 protein, male and female specific pathogen-free Hartley guinea pigs (with no exposure to chemicals; $\mathrm{n}=8$ for each sex) were used. They were anesthetized in ether, and then their livers were dissected. All the liver samples were stored at $-80^{\circ} \mathrm{C}$ until analysis.

2) Mice

This study was conducted according to the Animal Experimentation Guidelines of the Nagoya University Graduate School of Medicine. A pair of sv/129 genetic background parental cyp2e1-/- (CYP2E1-null) and cyp2e1+/+ (wild-type) mice were shipped to us from the Laboratory of Metabolism, National Cancer Institute, Bethesda, MD, USA. They were housed in a room with a 12 hours light: 12 hours dark cycle, stable relative humidity $(57-60 \%)$ and a constant temperature $\left(23-25^{\circ} \mathrm{C}\right)$ at the Institute of Laboratory Animal Research, Graduate School of Medicine, Nagoya University. Food and water were provided ad libitum. The mice were then bred, and ten CYP2E1null male offspring and 15 wild-type male offspring were used in this study. When the mice reached 13 weeks old (body weight approximately $25 \mathrm{~g}$ ), they were used for experiments.

\section{Chemical exposure}

1) Guinea pigs

All urine samples of guinea pigs were collected after the first challenge of TRI, TCA and TCE treatment in the GPMT, which was performed according to the OECD guideline ${ }^{17)}$. Forty-five male and female Hartley guinea pigs were randomly divided into 6 groups: ten animals from each sex were used for challenging with TRI, TCE and TCA, respectively, and animals from each sex were used in each of the respective control groups. Before the intracutaneous injection of a chemical, the dorsal skin on both sides of the scapular region $(4 \mathrm{~cm} \times 6 \mathrm{~cm})$ was shaved. Twenty-four hours after shaving to remove hair, each animal received the following three intracutaneous injections $(0.1 \mathrm{~m} l$ each): injection 1 , Freund's Adjuvant Complete (Sigma-Aldrich, St Louis, MO, USA); injection 2, the test material (5\% TRI in olive oil, $1.25 \%$ TCE in olive oil or $0.5 \%$ TCA in physiological saline); and injection 3, a 1:1 (v/v) mixture of injection 1 and 2 . After injection, the animals were placed in individual metabolic cages to collect urine for 24 hours. Control groups were intracutaneously injected with the same volume of olive oil alone instead of each test material. All the urine was stored at $-80^{\circ} \mathrm{C}$ until analysis.

2) Mice

In order to assess the involvement of CYP2E1 in TCE metabolism, 13-wk-old male wild-type $(n=10)$ and CYP2E1-null mice $(n=10)$ were used. TCE $(12.53 \mathrm{mg} / \mathrm{ml}, \mathrm{w} / \mathrm{v})$ was orally administered at a volume of $4 \mathrm{ml} / \mathrm{kg}$ body weight. After the administration, mice were placed in individual metabolic cages to collect urine for 24 hours. All samples were stored at $-80^{\circ} \mathrm{C}$ until analysis.

To determine the effect of exposure routes on the metabolism of the TCE, 13-wk-old male wild-type mice $(n=5)$ were intracutaneously treated with TCE $(12.53 \mathrm{mg} / \mathrm{ml}, \mathrm{w} / \mathrm{v})$ at a volume of $4 \mathrm{ml} / \mathrm{kg}$ body weight. After administration, mice were placed in individual metabolic cages to collect urine over a 
24 hours period. All urine was stored at $-80^{\circ} \mathrm{C}$ until analysis.

\section{Metabolites of TRI in urine by GC-MS}

Urinary TCA and TCE concentrations were measured by gas chromatography-mass spectrometry (GC-MS) under the analytic conditions referred to in a previous report ${ }^{11}$ with slight modifications. $\beta$-Glucuronidase (196 U) was added to urine samples (200 Q1) diluted 4-fold with water and incubated overnight at $37^{\circ} \mathrm{C}$. Forty-five microliters of $0.1 \mathrm{M}$ sulfuric acid was added to the hydrolyzed urine sample plus an internal standard (dichloroacetic acid, $200 \mathrm{mM}$ in methanol, $5 \mu l$ ). The sample was then mixed with $500 \mu l$ of water- $0.1 \mathrm{M}$ sulfuric acid-methanol (6:5:1) and heated at $70^{\circ} \mathrm{C}$ for 10 minutes to produce the derivatives. After cooling to room temperature, $500 \mu l$ of hexane-ethyl acetate $(3: 7)$ was added to the mixture for extraction, and the mixture was then mixed with a shaker for 20 minutes. The mixture was centrifuged at $3,000 \times \mathrm{g}$ for 10 minutes, and the supernatant solution $(1 \mu l)$ was injected into the GC-MS. Details of the GC-MS method (6890N GC, 5975 MS, 7683B series injector, 7683 series autosampler, Agilent Technologies, Santa Clara, CA, USA) were as follows: capillary column, Rtx-65; carrier gas, helium with a velocity of $1.0 \mathrm{ml} / \mathrm{min}$; oven temperature, $50^{\circ} \mathrm{C}$ for 3 min, temperature increased by $50^{\circ} \mathrm{C} / \mathrm{min}$ until $200^{\circ} \mathrm{C}$, and then $200^{\circ} \mathrm{C}$ for 5 minutes; temperature of injection port, MSD transfer line, ion source and quadrupole, were $150,280,230$, and $150^{\circ} \mathrm{C}$, respectively; analysis mode, EI; positive ion, $70 \mathrm{eV}$; and SIM parameters, $\mathrm{m} / \mathrm{z} 59$ for dichloroacetic acid (internal standard), m/z 49 for TCE and $\mathrm{m} / \mathrm{z} 59$ for TCA. Under the above conditions, the detection limits of TCA and TCE were $0.22 \mathrm{mg} / l$ and $0.10 \mathrm{mg} / l$, respectively. The amounts of TCA and TCE in the urine were expressed as the total amount using the urine volume.

\section{Western blot analysis}

Livers of 5 male wild-type and CYP2E1-null control mice ${ }^{11}$ were used to analyze hepatic expression of CYP2E1 protein. Sections of livers from control group guinea pigs and wild-type and CYP2E1null mice were each homogenized with three volumes of $10 \mathrm{mM}$ phosphate buffer ( $\mathrm{pH} 7.4$ ) containing $0.25 \mathrm{M}$ sucrose. A sample of liver homogenates was subjected to $10 \%$ polyacrylamide gel electrophoresis and then transferred to PVDF membranes. After blocking with $3 \%$ nonfat milk in Tris-buffered saline (TBS) for 1 hour at room temperature, membranes were incubated with primary polyclonal antibody against CYP2E1 (Abcam, Cambridge, UK), overnight at $4^{\circ} \mathrm{C}$. After washing the membranes with TBS and TBS containing $0.05 \%$ Tween-20, the membranes were incu-

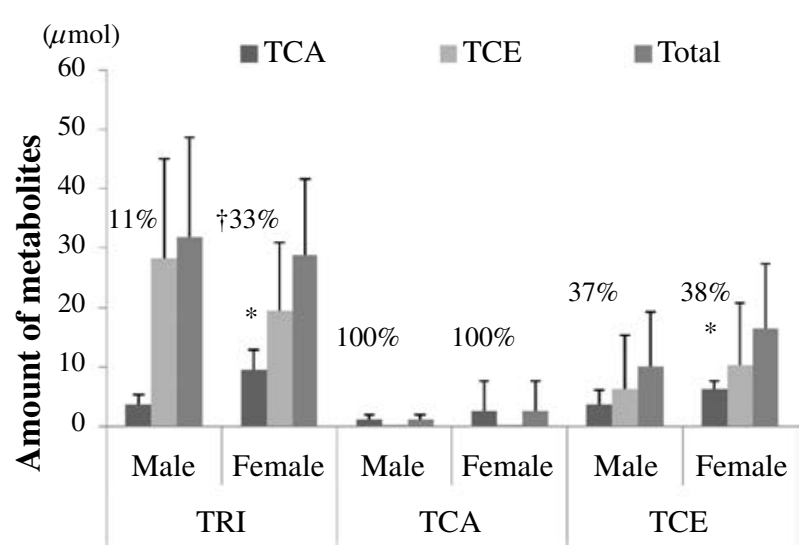

Fig. 1. Amounts of trichloroacetic acid (TCA) and trichloroethanol (TCE) in urine of guinea pigs intracutaneously exposed to TRI, TCA and TCE. Values represent means \pm SD for 10 guinea pigs per group. The values above the columns for TCA represent the percentages of total metabolites (TCA + TCE). *A significant difference was observed in the amount of TCA between males and females $(p<0.05) .{ }^{\dagger} \mathrm{A}$ significant difference in the percentage of TCA between males and females $(p<0.05)$.

bated with alkaline phosphate-conjugated goat antirabbit IgG (Jackson ImmunoResearch, West Grove, PA, USA). The specific immune complexes were detected using 1-Step ${ }^{\mathrm{TM}}$ NBT/BCIP Solution (Pierce Biotechnology, Rockford, IL, USA). The band was quantified by densitometry using CS Analyzer 3.0 (ATTO Corporation, Tokyo, Japan).

\section{Statistical analysis}

Data were expressed as means \pm SD. The Student's $t$ test was used to compare arithmetic means between males and females. In all analyses, $p$ values less than 0.05 were regarded as significant.

\section{Results}

Urinary metabolites in guinea pigs

Neither TCE nor TCA was detected in urine of any control group. However, as shown in Fig. 1, TCA and TCE were detected in the urine of male and female guinea pigs intracutaneously treated with TRI. Although the total amounts of TCA and TCE were not different between males and females, TCA excreted in urine was significantly greater in females than males, and therefore, the percentages of TCA were also significantly greater in urine of females $(33 \%)$ than males $(11 \%)$.

Only TCA was detected equally in the urine of both males and females after intracutaneous treatment with TCA.

Both TCE and TCA were detected in the urine of males and females intracutaneously treated with TCE. 


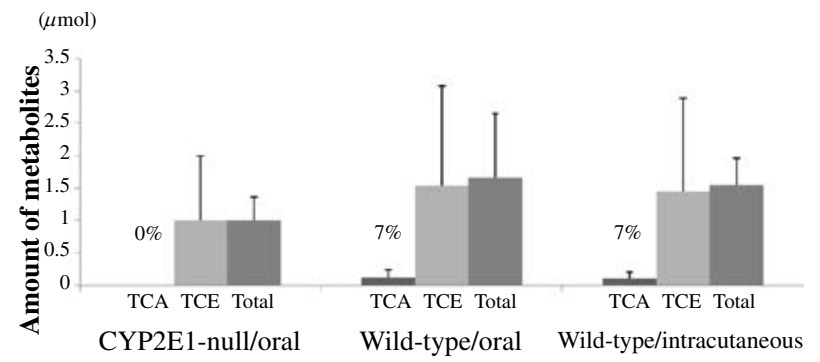

Fig. 2. Amounts of trichloroacetic acid (TCA) and trichloroethanol (TCE) in urine of wild-type mice $(n=10)$ and CYP2E1-null mice $(n=10)$ orally exposed to TCE and wild-type mice $(n=5)$ intracutaneously exposed to TCE. The values above the columns represent TCA percentages. Values represent means \pm SD for 5 or 10 mice per group. The values above the columns for TCA represent the percentages of total metabolites (TCA + TCE). *Significant difference in amount of urinary TCA between genotypes $(p<0.05)$.

TCA excreted in urine was significantly greater in females than males. However, the percentage of TCA relative to total metabolites did not differ between sexes after TCE treatment.

\section{Urinary metabolites in wild-type and CYP2E1-null} mice

Wild-type and CYP2E1-null mice were orally treated with TCE, and urinary TCE and TCA were measured. In the wild-type mice, both TCE and TCA were detected in the urine, and the percentage of TCA was $7 \%$ (Fig. 2). In contrast, only TCE was detected in the urine of CYP2E1-null mice. The amounts of TCE and TCA tended to be higher in the wild-type mice than those of TCE in CYP2E1-null mice, but there was no significant difference between the two. When the same dose of TCE was intracutaneously given to wild-type mice, both TCE and TCA were detected, and the percentage of TCA was the same $(7 \%)$ as that with oral treatment. No difference was noted in the total amount of TCE and TCA between the two treatment methods.

\section{Immunological detection of CYP2E1}

We also analyzed $C Y P 2 E 1$ in the livers of both sexes of nonexposed guinea pigs and male wildtype and $C Y P 2 E 1$-null mice by Western blot analysis. As shown in Fig. 3, the CYP2E1 band was detected by anti-CYP2E1 in the liver of mice as well as guinea pigs. The density of the band in the liver of mice was slightly higher than that in guinea pigs. However, in guinea pigs, the band was stronger in females than males. No band was detected in the livers of $C Y P 2 E 1$-null mice.
A

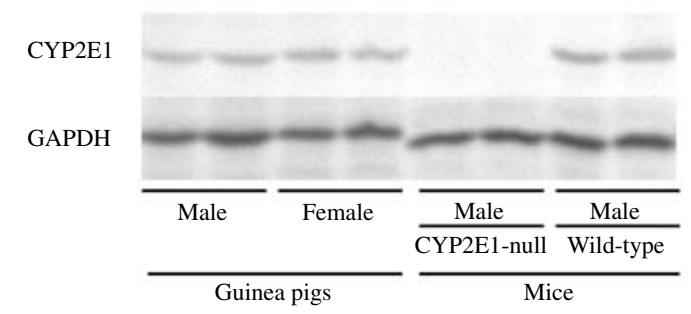

B

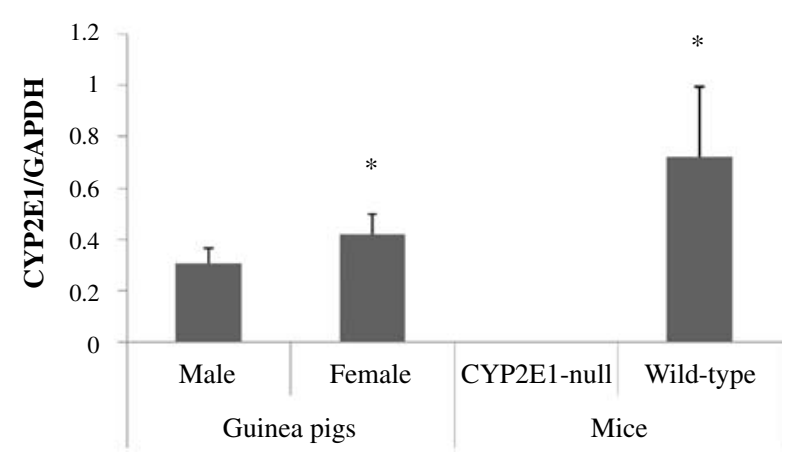

Fig. 3. CYP2E1 protein expression in the livers of non-treated male and female guinea pigs and mice. (A) Western blot analysis of CYP2E1 protein in two samples of each animal. (B) Band strength adjusted by GAPDH. The bands were quantified by densitometric analysis. The columns present means \pm SD values for 8 male and 8 female guinea pigs and 6 wild and 6 CYP2E1null mice. *Significantly different from male guinea pigs $(p<0.05)$.

\section{Discussion}

TCA is known to be produced from TRI as well as TCE via chloral hydrate in rats ${ }^{12)}$. The present study showed a similar pathway in guinea pigs. Interestingly, TCA production was greater in females than males among the animals studied in both chemical treatments: a sex difference existed in the production of TCA. An additional study using CYP2E1-null mice demonstrated that CYP2E1 was clearly involved in TCA formation from TCE in mice. There was no TCA in the urine of the null mice exposed to TCE, suggesting that CYP2E1 is a major form in the metabolic step, in addition to TRI metabolism ${ }^{10,11,16,18)}$. Since constitutive expression of CYP2E1 was significantly greater in females than males, the sex difference in TCA excretion in urine of guinea pigs may be explained by the difference of CYP2E1 expression in the livers: in females, the higher expression may contribute to either metabolism of TRI to TCA or metabolism of TCE to TCA. Thus, after TRI treatment, the percentage of TCA relative to total 
metabolites (TCA + TCE) was also greater in female guinea pigs but showed a similar value in both sexes after TCE treatment. This may be due to the different contributions of CYP2E1: in the former case, this isozyme was involved in two steps, TRI to TCA and TCE to TCA, via chloral hydrate, while in the latter case, the isozyme was involved only in one pathway from TCE to TCA.

In TRI treated male guinea pigs, the percentage of urinary TCA relative to total metabolites $(\mathrm{TCA}+\mathrm{TCE})$ was $11 \%$. In male wild-type mice, the percentage of TCA was $9 \%{ }^{19)}$, and this was very similar to that of male guinea pigs. In humans, the percentages of TCA excreted in urine of 15 men were reported to be $7-12 \%{ }^{20)}$, though the percentages increased over time with exposure: after one or two weeks of exposure to TRI, a high level of TCA was detected in urine of patients with generalized dermatitis complicated with hepatitis, but only a small amount of TCE was observed $^{21)}$. In male rats, the percentages were reported to be $1-3 \%^{16}$, which were less than those reported in mice ${ }^{22)}$, humans ${ }^{20)}$ or guinea pigs. Therefore, the excretion rate of TCA from male guinea pigs after TRI exposure was similar to that of mice and humans but different from that of rats, although the exposure route was different, with guinea pigs being treated subcutaneously.

The amount of CYP2E1 detected by anti-CYP2E1 was greater in female guinea pigs than males. The band detected by the antibody appeared to be greater in the liver of male mice than in that of male guinea pigs however, because the affinity of the antibody to the livers of the two animals may be different, further study is warranted to pinpoint the exact expression. However, the similar urinary excretion percentages of TCA after TRI treatment between mice and guinea pigs suggest that the constitutive expression of CYP2E1 in the liver may not be different between them. The constitutive expression of CYP2E1 was reported to be smaller in the liver of rats than mice ${ }^{23)}$. Taken together, the difference in the constitutive expression of CYP2E1 may contribute to the different percentages of TCA after TRI treatment among species. The constitutive expression of CYP2E1 in the liver of female guinea pigs was greater than that in the liver of male guinea pigs, which may also have contributed to the higher sensitization of TCE in females, because there is no sensitization in males ${ }^{14}$.

In humans, the amount of urinary TCA was 2-3 times higher in women than in men for the first 24 hours after TRI exposure ${ }^{24}$, suggesting that a sex difference in TRI metabolism may exist in humans. However, the contribution of CYP2E1 was unknown. In rats, sex differences were observed in the metabolism of toluene ${ }^{25)}$ and styrene ${ }^{26)}$ at the adult stage, because male-specific CYP2C11 increases with aging ${ }^{25,27)}$. Although CYP2E1 was constitutively expressed at a similar level in the liver of 3-wk-old male and female rats, it decreased more prominently in males than females with aging, resulting in a sex difference in this isoform at the mature stage ${ }^{25-27)}$. Increased CYP2C11 but decreased CYP2E1 with aging in male rats may reset the sex difference in the metabolism of TRI at the mature stage in rats ${ }^{25}$. However, in this study, the expression of CYP2E1 was apparently higher in female guinea pigs than males; therefore, a sex difference in TRI and TCE metabolism was observed in guinea pigs.

As described previously, CYP2E1 is a key enzyme in TRI-induced hepatotoxicity, as shown by the fact that CYP2E1-null mice could not express hepatotoxic potential after the exposure ${ }^{11)}$. Additionally, this isoform has an important role in TRI-induced autoimmune hepatitis ${ }^{7}$. Halothane had been used as an anesthetic agent however, it causes fatal severe hepatitis in rare settings ${ }^{28}$. CYP2E1 is a major catalyst in the formation of trifluoroacetylated proteins, which have been implicated as target antigens in the mechanism of halothane hepatitis; immune responses to cell surface CYP2E1 could also be involved in the pathogenesis of halothane hepatitis ${ }^{29)}$. If CYP2E1 is involved in TRI-induced generalized hypersensitive dermatitis, the involvement of this isoform in metabolism of TCE to TCA may also be an important issue because TCE was shown to have a weak hypersensitive potential, especially in female guinea pigs ${ }^{14)}$. This also suggests that TCE may be involved in TRI-induced generalized skin damage with hepatitis ${ }^{9)}$. Although TRI-induced acute hepatitis has also been reported, the involvement of CYP2E1 was unknown.

We investigated the metabolism of TRI and TCE in guinea pigs using only one dose. In rats, TRI is dose-dependently metabolized up to $2,000 \mathrm{ppm}^{16)}$, but no information on the TCE metabolism has been reported. We were unable to comprehend the difference in metabolic capacity of TRI between rats and guinea pigs. In male rats, $573 \pm 94 \mu \mathrm{mol} / \mathrm{kg}$ (mean $\pm \mathrm{SD}$, mean value was about $191 \mu \mathrm{mol} / \mathrm{rat}$ ) of metabolites (TCA + TCE) were excreted in urine over the course of 24 hours after exposure to $500 \mathrm{ppm}$ TRI for 2 hours ${ }^{16)}$. This amount is much higher than the value, $31.9 \pm 16.6 \mu \mathrm{mol} / \mathrm{male}$ guinea $\mathrm{pig}$, in the current study. Although the exposure route also differed between the current guinea pig experiment and that performed in rats in the past, the dose used in this study does not appear to be too high, and so it is possible that TRI metabolism occurs in a dosedependent range.

In conclusion, there was a clear-cut sex difference in the metabolism of either TRI or TCE in guinea 
pigs. The higher expression of CYP2E1 in the liver of female guinea pigs may be primarily involved in the sex difference.

Acknowledgments: This work was supported by a Grant-in-Aid for Scientific Research (24659299 and 24406019) from the Japan Society for the Promotion of Science and was funded by a Grant (2010B050700026) from the Science and Technology Planning Project of Guangdong Province, China.

\section{References}

1) Yu JF, Leng J, Shen $T$, et al. Possible role of complement activation in renal impairment in trichloroethylene-sensitized guinea pigs. Toxicology 2012; 302: 172-8.

2) Chiu WA, Jinot J, Scott CS, et al. Human health effects of trichloroethylene: key findings and scientific issues. Environ Health Perspect 2013; 121: 303-11.

3) Forkert PG, Lash LH, Nadeau V, Tardif R, Simmonds A. Metabolism and toxicity of trichloroethylene in epididymis and testis. Toxicol Appl Pharmacol 2002; 182: 244-54.

4) Mensing $T$, Welge P, Voss B, et al. Renal toxicity after chronic inhalation exposure of rats to trichloroethylene. Toxicol Lett 2002; 128: 243-7.

5) Kamijima M, Hisanaga N, Wang $H$, Nakajima $T$. Occupational trichloroethylene exposure as a cause of idiosyncratic generalized skin disorders and accompanying hepatitis similar to drug hypersensitivities. Int Arch Occup Environ Health 2007; 80: 357-70

6) Nakajima T, Yamanoshita O, Kamijima M, Kishi R, Ichihara G. Generalized skin reactions in relation to trichloroethylene exposure: a review from the viewpoint of drug-metabolizing enzymes. J Occup Health 2003; 45: 8-14.

7) Griffin JM, Gilbert KM, Lamps LW, Pumford NR. CD4(+) T-cell activation and induction of autoimmune hepatitis following trichloroethylene treatment in MRL+/+ mice. Toxicol Sci 2000; 57: 345-52.

8) Kaneko T, Saegusa M, Tasaka K, Sato A. Immunotoxicity of trichloroethylene: a study with MRL-lpr/lpr mice. J Appl Toxicol 2000; 20: 471-5.

9) Huang H, Kamijima M, Wang $H$, et al. Human herpesvirus 6 reactivation in trichloroethyleneexposed workers suffering from generalized skin disorders accompanied by hepatic dysfunction. J Occup Health 2006; 48: 417-23.

10) Nakajima T, Wang RS, Elovaara E, Park SS, Gelboin HV, Vainio H. A comparative study on the contribution of cytochrome $\mathrm{P} 450$ isozymes to metabolism of benzene, toluene and trichloroethylene in rat liver. Biochem Pharmacol 1992; 43: 251-7.

11) Ramdhan DH, Kamijima $M$, Yamada $N$, et al. Molecular mechanism of trichloroethylene-induced hepatotoxicity mediated by CYP2E1. Toxicol Appl Pharmacol 2008; 231: 300-7.
12) Ikeda M, Miyake Y, Ogata M, Ohmori S. Metabolism of trichloroethylene. Biochem Pharmacol 1980; 29: 2983-92.

13) Tang X, Que B, Song X, et al. Characterization of liver injury associated with hypersensitive skin reactions induced by trichloroethylene in the guinea pig maximization test. J Occup Health 2008; 50: 114-21.

14) Hibino $Y$, Naito H, Saito $Y$, et al. A study on immunological liver injury induced by trichloroethylene exposure. Nihon Eiseigaku Zasshi 2012; 67: 264.

15) Gilbert KM, Przybyla B, Pumford NR, et al. Delineating liver events in trichloroethylene-induced autoimmune hepatitis. Chem Res Toxicol 2009; 22: 626-32.

16) Nakajima T, Okino $T$, Okuyama S, Kaneko $T$, Yonekura I, Sato A. Ethanol-induced enhancement of trichloroethylene metabolism and hepatotoxicity: difference from the effect of phenobarbital. Toxicol Appl Pharmacol 1988; 94: 227-37.

17) OECD. OECD Guideline for the Testing of Chemicals "Skin Sensitisation". Organisation for Economic Co-operation and Development 1992.

18) Nakajima T, Wang RS, Elovaara E, et al. Toluene metabolism by cDNA-expressed human hepatic cytochrome P450. Biochem Pharmacol 1997; 53: 271-7.

19) Ramdhan DH, Kamijima M, Wang D, et al. Differential response to trichloroethylene-induced hepatosteatosis in wild-type and PPARalphahumanized mice. Environ Health Perspect 2010; 118: 1557-63.

20) Vesterberg O, Astrand I. Exposure to trichloroethylene monitored by analysis of metabolites in blood and urine. J Occup Med 1976; 18: 224-6.

21) Kamijima $M$, Wang $H$, Huang $H$, et al. Trichloroethylene causes generalized hypersensitivity skin disorders complicated by hepatitis. J Occup Health 2008; 50: 328-38.

22) Prout MS, Provan WM, Green T. Species differences in response to trichloroethylene. I. Pharmacokinetics in rats and mice. Toxicol Appl Pharmacol 1985; 79: 389-400.

23) Nakajima T, Wang RS, Elovaara E, Park SS, Gelboin HV, Vainio H. Cytochrome P450-related differences between rats and mice in the metabolism of benzene, toluene and trichloroethylene in liver microsomes. Biochem Pharmacol 1993; 45: 1079-85.

24) Nomiyama K, Nomiyama H. Metabolism of trichloroethylene in human. Sex difference in urinary excretion of trichloroacetic acid and trichloroethanol. Int Arch Arbeitsmed 1971; 28: 37-48.

25) Nakajima T, Wang RS, Katakura Y, et al. Sex-, ageand pregnancy-induced changes in the metabolism of toluene and trichloroethylene in rat liver in relation to the regulation of cytochrome P450IIE1 and P450IIC11 content. J Pharmacol Exp Ther 1992; 261: 869-74.

26) Kishi R, Sata F, Katakura Y, Wang RS, Nakajima T. 
Effects of pregnancy, age and sex in the metabolism of styrene in rat liver in relation to the regulation of cytochrome P450 enzymes. J Occup Health 2005; 47: 49-55.

27) Thomas PE, Bandiera S, Maines SL, Ryan DE, Levin W. Regulation of cytochrome P-450j, a highaffinity $\mathrm{N}$-nitrosodimethylamine demethylase, in rat hepatic microsomes. Biochemistry 1987; 26: 2280-9.

28) Kenna JG, Neuberger JM. Immunopathogenesis and Treatment of Halothane Hepatitis. Clinical Immunotherapeutics 1995; 3: 108-24.

29) Eliasson E, Kenna JG. Cytochrome P450 2E1 is a cell surface autoantigen in halothane hepatitis. Mol Pharmacol 1996; 50: 573-82. 